\title{
General assessment of the environmental status and environmental risks in the Arctic zone of the Russian Federation
}

\author{
$E V$ Vorontsova $^{1,{ }^{*}, \text { and } A} L$ Vorontsov $^{1}$ \\ ${ }^{1}$ Southwest state University, Kursk, Russian Federation
}

\begin{abstract}
The article presents an assessment of the current ecological status of the Arctic zone of the Russian Federation as a promising area of active industrial development. Acknowledging the current negative environmental consequences of human activities in the Arctic, the authors raise the issue of environmental risks in the Arctic region, which inevitably arise due to the intensification of resource extraction in these areas. From the standpoint of a risk-based approach, the authors insist on the need to take into account the environmental safety requirements in the Arctic region when conducting any kind of business and other activities, taking into account the particular vulnerability of the Arctic ecosystems and the climate-forming significance of this region for the entire planet. In their opinion, at present, the problem of environmental safety in the Russian Arctic is aggravated by several unfavorable factors: environmental damage accumulated over a long period of previous economic and military activities; the lack of the necessary legal framework to regulate resource extraction activities in the region, taking into account new environmental requirements; Russia's lack of the latest eco-friendly technologies for offshore hydrocarbon production. Each of these factors is capable of provoking irreversible environmental consequences, and, accordingly, each of them should be subjected to in-depth scientific evaluation in the framework of strategic and project-economic planning.
\end{abstract}

\section{Introduction}

In the 21 st century, industrial development of the Arctic is becoming a factor of civilizational development for all of humanity. It is difficult to argue with this opinion, since natural resources, concentrated in other parts of the planet, have long been included in the production and technological turnover and have been largely exhausted. According to experts, some of them can be fully utilized during the life of a single generation. This creates a bleak prospect not only for world industrial production, but also for every inhabitant of the Earth, since our grandchildren can already be in the absence of the necessary material and raw material base of their existence.

Awareness of this circumstance stimulates the active interest of the world community to the potential of the Arctic region, the use of which can create guarantees of sustainable development for the world economy and civilization as a whole. Already in this region, $40 \%$ of world production of palladium, $20 \%$ of diamonds, $15 \%$ of all extracted platinum, $10 \%$ of nickel, $11 \%$ of cobalt, $9 \%$ of tungsten and $8 \%$ of zinc are mined. In addition, coniferous forests of the Arctic territories make up $8 \%$ of world timber reserves. In addition, the Arctic has a significant amount of bioresources - up to $10 \%$ of world fisheries can be provided by the Arctic seas (Borgerson Scott G., 2013). The hydrocarbon potential of the Arctic region is also huge. Back in 2007, hydrocarbon reserves in this region were estimated at 412 billion barrels (according to the United States Geological Survey, USGS), with most of these reserves located on the continental shelf of the Arctic territories, including in Russia, on the eastern shelf of the Barents Sea. As for unexplored gas resources, more than $70 \%$ of them are concentrated in three regions of the Arctic, two of which - the Arctic territories of Western Siberia and the eastern shelf of the Barents Sea - belong to Russia. According to information provided by the US Department of Energy, along with oil, these reserves make up at least $22 \%$ of world energy resources.

The above pushes our country to the active development of the natural resources of the Arctic, especially since almost a third of its total area belongs to Russia. The official position of our state on this issue was expressed on December 14, 2017 during the ongoing traditional big press conference, President V.V. Putin, who said, "Now Russia's wealth must grow in the Arctic. There our main reserves of mineral raw materials. However, the development of these mineral reserves must go hand in hand with the care for nature, with all the requirements that are imposed on economic activities in this very sensitive region". (Vladimir Putin, 2017).

Global climate change is also contributing to the advancement of humankind to the Arctic, leading to a reduction in ice cover. For our country, this creates conditions for more sustainable use and development of

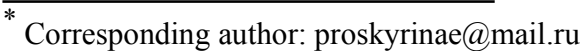


resources (especially on the shelf), expands the possibilities of using shipping (the Northern Sea Route is capable of fundamentally changing global logistics) and leads to an increase in the marine area available for fishing. However, the displacement of the ice boundary to the north creates a direct threat to the arctic flora and fauna. And the main problem, in our opinion, is not even that the melting of the Arctic ice reduces the living space for certain types of animals and plants. The anthropogenic load may become a much more important problem for the Arctic environment, which will disproportionately increase due to the intensification of the resource-producing activities of not accessible territories. Moreover, if the absence of floating ice can multiply reduce the number of some populations (but still only reduce it), then the consequences of human economic activity can lead to their complete disappearance. Moreover, the negative impact of the anthropogenic factor on the person himself will increase significantly (not only in the Arctic region, but also in other territories, taking into account the climate-forming significance of the Arctic).

The circumstances mentioned above cannot be ignored in the course of the industrial development of the resources discovered in the Arctic. This is prompted by the particular vulnerability of the Arctic ecological systems. Thus, the opportunities provided to our country can be fully used only if the requirements of environmental safety are observed. Otherwise, all the benefits from the use of Arctic resources will be canceled out by the environmental consequences of our activities, which in the conditions of the Arctic will be simply catastrophic.

As it seems to the authors of this article, while carrying out a new "rush to the Arctic", Russia should objectively assess the possible risks of such an expansion. In addition, environmental risk is, in our opinion, the main one, since it can result in not only irreversible harm to the environment, but also enormous economic, social and even political consequences.

The problem of environmental safety in the Arctic region of the Russian Federation is exacerbated by several adverse factors: environmental damage accumulated during the years of previous economic and military activities; our country's lack of advanced environmental technologies for offshore operations; lack of due level of legal regulation of industrial activity in the Arctic zone. All these factors require their in-depth study in the framework of strategic and projecteconomic planning, during which the opinion of the scientific community should be leading.

These guidelines, written in the style of a submission to J. Phys.: Conf. Ser., show the best layout for your paper using Microsoft Word. If you don't wish to use the Word template provided, please use the following page setup measurements.

\section{Materials and methods}

The multidimensionality and complex nature of the problem we are investigating initially determined the interdisciplinary approach to its analysis. The fact is that the study of problems of environmental safety in the Arctic for many years was carried out, as a rule, within the framework of industry research, which to a certain extent predetermined their substantive limitations and did not allow developing scientific cooperation to the proper extent. The needs of the time force us to change the methodological approaches and in our work, we sought to synthesize scientific perspectives of various specialties. In our opinion, this approach leads to a holistic perception of the problem of ensuring environmental safety in the Arctic and contributes to the development of the most optimal proposals for its resolution.

In general, we studied the problem of ensuring environmental safety from the standpoint of a new, probabilistic safety paradigm based on the assessment of a multitude of risks.

The environmental legal assessment of the current state of the environment in the Arctic zone objectively predetermined the use of the analysis method as the main tool of scientific knowledge of the problem under study. In addition, the statistical method is widely used (in assessing the dynamics of pollution of the Arctic territories), as well as the method of scientific forecasting (futurological method) as a method of prospective assessment of the possible development of the environmental situation in the Arctic zone.

\section{Results and discussion}

The Arctic zone of the Russian Federation includes the mainland, marine areas, archipelagoes and islands. The land territory of the Arctic zone makes up about $30 \%$ of the territory of Russia. The variety of geological settings within the Arctic zone predetermined the formation of about 50 types of mineral deposits here. In the Arctic zone, most Russian hydrocarbon deposits are concentrated: about 600 oil fields and more than 150 gas, two nickel fields and more than 350 gold. Arctic reserves provide about $11 \%$ of Russia's national income and almost a quarter of total Russian exports (Donskoy S.E., 2013 , p.7). $43 \%$ of the territory of the Arctic zone are recognized as promising for oil and gas, including 71\% of the shelf area (Tkachev V.P., 2015, p.210). As for the shelf, back in 2013, the then Minister of Natural Resources of the Russian Federation, S.E. Donskoy, predicted that "... as a result of the development of the Arctic shelf, the capitalization of the Russian oil and gas sector will be about $\$ 150$ billion, the state budget will receive about 1.5 trillion additional tax revenues, and the country's GDP will increase by 3\% " (Donskoy S.E., 2013 , p.7). At the same time, the development of offshore hydrocarbon deposits is the most dangerous type of economic activity, coupled with the likelihood of accidents and disasters at the facilities of these fields. Let us not forget that in general in oil and gas producing regions the magnitude of environmental risk is 1-2 orders of magnitude higher than the average for the Russian Federation in areas subject to combined anthropogenic impact (Anikeev V.V., Rybina E.S., 
Bakshin V.N., 2005, p.110), and in Russia, according to official statistics, more than 20,000 accidents occur every year. oil production. In this case we are talking about accidents at the facilities of the oil industry (primarily on oil pipelines) located on land. Work at sea carries special environmental risks, especially in the Arctic, where the possibility of eliminating the consequences of emergencies is complicated by the conditions of the polar night, numerous storms with high waves, thick fog, multi-meter ice and the possibility of collision with icebergs (Kondratieva V.I., Lukin Yu.F., 2015, p. 159).

The risk of the operation of energy companies in the Arctic due to the lack of emergency response practices in ice conditions is particularly emphasized by specialists from the regional departments of the Russian Emergencies Ministry located in the Arctic zone. In addition, some natural and climatic features of the Russian Arctic shelf zone (direction of sea currents, wind rose, etc.) contribute to the spread of possible pollution over a large area. For example, according to a study on the Prirazlomnaya platform (the Kara Sea), over 140 thousand $\mathrm{km} 2$ of water area and 3,500 km of the coast (Tkachev V.P., 2015, p.210) fall into the risk zone of pollution from its activities.

Large environmental risks will create an intensification of the functioning of the Northern Sea Route (NSR), which is the main route for the delivery of oil, both for the domestic Russian consumer, and for the countries of Europe and America. Tankers used for the transportation of oil, as well as coastal transshipment complexes can become dangerous potential sources of pollution, both in the sea and in the coastline.

Do not forget about the transportation of liquefied gas. According to experts, global demand for gas will increase by more than $40 \%$ by 2040 and, most importantly, the supply of liquefied gas will most actively develop. Here growth can reach $70 \%$. Russia is capable and should occupy a worthy niche in this market, President of the Russian Federation Vladimir Putin said on December 8, 2017 at a meeting on the development of projects for the production of liquefied natural gas held during a visit to the Yamal LNG plant. However, an increase in the intensity of maritime transport, as well as the development of the infrastructure of the gas industry in the Arctic, will increase the risks of adverse environmental impacts of the region. The first to suffer will be the atmosphere of the Arctic zone, which is currently being subjected to a very powerful anthropogenic impact due to flaring of associated petroleum gas, as well as emissions from industrial enterprises of the mining industry.

Pollution of the atmosphere of the Arctic zone is also objectively promoted by the fact that in this area there is an unloading of airflows from all anthropogenic elements, accumulated in temperate latitudes. As a result, atmospheric dust of the Arctic region contains copper, nickel, cadmium, lead, and sulfur in significant quantities. These elements are part of the atmospheric aerosol, which directly enters the body of humans and animals, and settles on the surface of the soil and the Arctic seas. As for the latter, in terms of their impact on the chemical composition of the Arctic seas, atmospheric aerosols are quite comparable with river flows. For example, the average annual amount of pollution of the waters of the Kara Sea and the central part of the Laptev Sea by cadmium and lead, produced through atmospheric aerosols, is $30-50 \%$ of the amount of pollution produced by wastewater (Izrael Yu.A., Tsyban A.V., 2009).

Among the components of the Arctic air aerosol, a significant proportion of the sulphates are, the presence of which leads to oxidation and contamination of precipitation. Falling on snow, ice, soil and water, these sediments directly affect their chemical composition. In addition, carbon is present in precipitation (in the form of soot), which changes the radiation background of the atmosphere, which makes this factor the main climateforming factor in the Arctic (Nemirovskaya I.A., 2013).

The main role in the processes of air pollution in the Arctic is played by the mining industry. Of the 9.2 million tons of sulfur dioxide (SO2) emitted annually into the atmosphere by Russian enterprises 16, more than 3 million tons are emitted by mining enterprises (Gudkov A.B., Tedder Ju.R., 1999, №3). It should be noted that this sector of production, as a whole throughout Russia, is characterized by a significant load on the environment, which manifests itself in a change in the natural landscape and other negative consequences (Vorontsov A., Vorontsova E. Drozdenko Yu., 2017).

At the same time, in no other region of Russia, this leads to such dire consequences as in the Arctic zone. For example, in the territory of the Kuzbass coal basin (Kemerovo region), the volume of harmful substances emitted by mining enterprises is even higher (due to a higher concentration of production) than in the Arctic regions of a similar production profile. However, despite the fact that the environment in the Kemerovo region at the concentration sites of mining enterprises is one of the worst in Russia, the average concentrations of pollutants there are often lower than in similar regions of the Arctic zone. In addition, environmental remediation activities carried out in the Kemerovo Region lead to more tangible positive consequences than, say, in the Murmansk Region or in the north of the Krasnoyarsk Territory, where atmospheric air of several territories (for example, the cities of Monchegorsk and Norilsk) has, among other things, increased carcinogenic risk (Revich B.A., 2007), (Revich B. A., Kharkova T. L., Kvasha E. A., Bogoyavlensky D. D., Korovkin A. G., Korolev I. B., 2016).

In our opinion, one of the main reasons for this depressing situation is a special combination of unfavorable environmental factors, which in the conditions of the Extreme North leads to an effect not observed in other latitudes with the cumulative effect of similar factors. We call this effect "Arctic synergy" an adverse effect.

Arising as a result of the complex impact of negative climatic and anthropogenic factors, as well as the low ability of the Arctic nature to self-purification, the "arctic synergy" of adverse effects can lead to dramatic non-linear changes in the functioning of ecosystems. These changes are irreversible in nature and can be fatal. 
In our opinion, the "Arctic synergy" factor should be taken into account when building industrial development projects in the Arctic. Of course, this will require a change in the economic planning methodology (and the authors are aware of all the difficulties associated with this), but it simply cannot be otherwise, because otherwise one of the results of the economic activity in the Arctic zone will be total destruction of the environment. The paradigm of ensuring environmental safety in the Arctic (and not only) should change in the direction of moving away from the old system of establishing threshold values, maximum permissible concentrations (MPC), levels, etc. and reorient to a probabilistic model based on an assessment of possible risks. We do not in any way call for the rejection of the establishment of maximum permissible thresholds of sensitivity in relation to human health and the environment. They still have to play the instrumental role of a specific indicator of the hazard / harm of a particular impact.

However, they should not be the main criterion in the course of environmental and economic planning in the Arctic zone, since the characteristics of this territory can transform the impact of any of the factors, and not for the better. Proof of this may be the already mentioned effect of "Arctic synergy" of adverse effects.

In addition to oil spills (due to which some of the reindeer pastures have already been taken out of use) and atmospheric emissions from enterprises, the enormous environmental risks in the Russian Arctic are created by wastewater. They are subject to enormous technogenic impact due to the large number of mining and other enterprises in the coastal areas of the Arctic zone. Water bodies in the immediate vicinity of cities and industrial complexes, as well as the Arctic Ocean, where toxic substances get along with river flows, are subject to pollution. As for the latter, river basins, in our opinion, should have long ago become the primary object of study for environmental science. This is explained by the importance of surface runoff processes for changing the background characteristics of the arctic natural landscape. However, increased attention to this problem began to manifest itself only recently, when the situation approached a critical one.

The main pollutants in this case are petroleum hydrocarbons, iron and copper. As for closed water bodies (glacial lakes), lakes and rivers flowing into them, due to the continuous and long-term anthropogenic impact, their pollution has become chronic in a number of areas of the Arctic zone. This contributes to the accumulation of toxic chemicals in bottom sediments. For example, in the Purovsky District of the YamaloNenets Autonomous District, surface waters are so polluted because of oil spills that the average concentration of pollutants is $12-16$ times higher than the permissible levels. Largely, this is also due to the geographical position of the Arctic territories, in particular, the direction of the main rivers. Most of them flow into the Arctic Ocean, taking wastewater from other regions of the country throughout its length and causing damage to the environment downstream.
River runoff is the main source of pollution of the waters of the Kara and Barents seas. As for the latter, accidental emissions of ships, underwater pipelines, and leaks from transshipment terminals create additional anthropogenic load. In addition, the sea area near the Kola Peninsula is a zone of active navigation, which also contributes to the pollution of coastal waters. As a result, according to 2013, in the waters of the port of Murmansk, the content of petroleum hydrocarbons was 4.7 times higher than the MPC, manganese - 2.1 times, iron -8.8 times, the copper concentration exceeded the maximum allowable (MPC) 1.7 times. In addition, an elevated content of pesticides, lead, mercury and nickel was noted in the port waters.

To the chemical pollution of the waters of the Arctic seas is added their contamination with radioactive waste (especially in the Western Arctic). For a long time in the Arctic zone conducted tests of nuclear weapons. The consequences of these tests felt on themselves and people and the environment. With the cessation of explosions of nuclear devices, the technogenic impact of polygons did not disappear. On Novaya Zemlya and in the adjacent areas, active radiation is still observed. The risks of exposure to radionuclides are added by the presence of a large number of radiation hazardous objects located on the seabed: nuclear power plants of sunken submarines with spent nuclear fuel, submerged solid radioactive waste contaminated with radioactive substances, and elements of icebreakers. Existing civilian and military facilities also pose significant environmental risks, and there is currently no optimal way to solve this problem.

According to the authors of this article, we noted earlier the peculiarities of the ecological state of the Arctic zone, as well as the environmental risks arising in connection with this should be taken into account during the new stage of large-scale industrial development of the Arctic, which our country has undertaken. Ensuring the sustainable development of this region a priori implies ensuring environmental safety on its territory, and the neglect of this obvious truth can have truly disastrous consequences for Russia. Russian Federation is quite realized the danger of environmental threats and in attempts at organizational and legal counteraction to them is not limited to only general measures for environmental protection (Vorontsov A., Vorontsova E., Drozdenko Yu., 2018).

\section{Conclusion}

The analysis of the ecological status and possible environmental risks of industrial development of the Arctic zone of the Russian Federation carried out by the authors led to the following conclusions:

-the environment of the Arctic territories is a unique ecological system of global significance. The industrial development of these territories objectively carries with it a whole range of environmental risks that must be taken into account when creating business projects; 
-currently the main threats to the environment of the Arctic zone of the Russian Federation are created by the following anthropogenic factors:

1. Intensification of hydrocarbon production on the Arctic shelf. Work at sea carries special environmental risks, especially in the Arctic, where the possibilities of emergency response are significantly complicated by climatic conditions;

2. Deterioration of the infrastructure for the delivery of oil and gas. This leads to a consistently high level of accidents on oil pipelines. In general, in the oil and gas producing regions of Russia, the magnitude of environmental risk is 1-2 orders of magnitude higher than in the rest of the country;

3. Intensification of the functioning of the Northern Sea Route (NSR). Tankers used for transportation of oil, as well as coastal transshipment complexes can become very dangerous sources of pollution of the coast and waters of the Arctic Ocean;

4. Underdevelopment (or absence at all) of environmentally friendly technologies for the extraction of energy resources;

5. Sewage. Features of the Arctic ecosystems (low selfcleansing capacity, etc.), as well as the geographical location of the Arctic territories (this is where the mouths of the main rivers of the Urals and Siberia are located) contributes to the accumulation of toxic substances from other regions of the country;

6. The presence of significant amounts of radioactive waste in the Arctic Ocean (especially in the Western Arctic).

All the anthropogenic factors we have listed create enormous environmental risks, the neglect of which can lead to consequences on a global scale.

\section{References}

[1] V.V. Anikeev, E.S. Rybina, V.N. Bakshin, Analysis and management of environmental risk in the oil and gas producing regions of Russia, Actual problems of regulating natural and man-made safety in the XXI century: materials of the Xth International Scientific and Practical Conference on the problems of protecting people and territories from emergency situations, 19-21 April 2005, EMERCOM of Russia, M.: Ying-octave, 103-114 (2005).

[2] Scott G. Borgerson, The Coming Arctic Boom (As the Ice Melts, the Region Heats Up), Foreign Affairs, 4 (2013) [Electronic resource]. Available at: https://www.foreignaffairs.com/articles/globalcommons/2013-06-11/coming-arctic-boom.

[3] D.A. Dodin, L.K. Govorkova, M.A. Sadikov, Geoecological aspects of environmental monitoring in the Russian Arctic, Modern geodynamics, deep structure and seismicity of platform areas and adjacent regions: materials of the international conference., Voronezh, 73-75 (2001).

[4] S.E. Donskoy, Cold calculations, RBC-Daily, 25 September 2013, 176, 1709, 7 (2013).
[5] A.B. Gudkov, Ju.R. Tedder, Expedition shift work Schedule beyond the Polar Circle, Human Physiology, 25, 3, 370-373 (1999).

[6] Hydrocarbon resources of the Arctic in the context of geopolitics [Electronic resource]. Available at: https://mgimo.ru/about/news/inno/239858/.

[7] Yu.A. Izrael, A.V.Tsyban, Anthropogenic ecology of the ocean, M .: Science, 2009, 520 (2015).

[8] V.I. Kondratieva, Yu.F. Lukin, Arctic: Perspectives for Sustainable Development, Arctic and North, 18, 148-169 (2015).

[9] Meeting on the development of projects for the production of liquefied natural gas [Electronic resource]. Available at: https:/govnews.ru/news/705806.

[10] I.A. Nemirovskaya, Oil in the ocean (pollution and natural flows), Moscow: Nauchniy Mir, 432 (2013).

[11] Oil tears of Russia: accidents on oil pipelines provoke cancer [Electronic resource]. Available at: https://www.rbc.ru/economics/10/04/2012/5703f5c 09a7947ac81a66c05.

[12] B.A. Revich, T.L. Kharkova, E.A. Kvasha, D.D. Bogoyavlensky, A.G. Korovkin, I.B. Korolev, Demographic processes, labor force dynamics and public health risks in the European part of the Arctic zone of Russia, Ed. B.A. Revich, B.H. Porfir'eva, M .: LENAND, 304 (2016).

[13] B.A. Revich, "Hot spots" of chemical pollution of the environment and the health of the population of Russia, Ed. V.M. Zakharov, M.: Acropolis, Public Chamber of the Russian Federation, 192 (2007).

[14] Review of the state and environmental pollution in the Russian Federation in 2017 [Electronic resource]. Available at: http://www.meteorf.ru/upload/iblock/6f7/Obzor_20 17_Chernogaeva

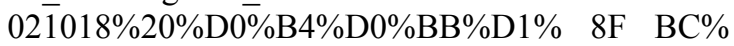
D0\% B5\% D1\% 89\% D0\% B5\% D0\% BD\% D0\% $\mathrm{B} 8 \%$ D1\% 8F\% 20\% D0\% BD\% D0\% B0\% 20\% D1\% 81\% D0\% B0\% D0\% B9\% D1\% 82\% D0\% B5.pdf.

[15] Review of the state and environmental pollution in the Russian Federation for 2013 [Electronic resource]. Available at: http://www.meteorf.ru/upload/iblock/23f/Obzor_20 13 by_Chernogaeva $16072014 . p d f$.

[16] V.P. Tkachev, Risks of environmental management of oil and gas producing regions of the North (Arctic), Northern region: science, education, culture, 2, 32, II, 210-215 (2015).

[17] US Department of Energy: $22 \%$ of the world's oil and gas reserves are located in the Arctic [Electronic resource]. Available at: https://vz.ru/news/2009/10/21/340412.html.

[18] Vladimir Putin: Now the wealth of Russia must grow in the Arctic [Electronic resource]. Available at: http://s-vesti.ru/news/oficialno/17157-vladimirputin-teper-bogatstvo-rossii-dolzhno-prirastatarktikoy/. 
[19] A. Vorontsov, E. Vorontsova, Yu. Drozdenko, Organizational-legal and technological aspects of ensuring environmental safety of mining enterprises: perspective analysis in the context of the general enhancement of environmental problem, E3S Web of Conferences The Second International Innovative Mining Symposium (2017).

[20] A. Vorontsov, E. Vorontsova, Yu. Drozdenko, Legal Support of Environmental Safety as a Reaction of the Russian State to Environmental Threats, E3S Web of Conferences The Second International Innovative Mining Symposium (2018).

[21] Yamal has already felt the negative consequences of the development of the Arctic [Electronic resource].

Available

at:

https://regnum.ru/news/1697770.html. 